\title{
SUBSÍDIOS PARA A CONSTRUÇÃO DO PROJETO POLÍTICO-PEDAGÓGICO EM ESCOLAS MUNICIPAIS
}

Flávio Caetano da Silva

Celso Luiz Aparecido Conti

UFSCar

\section{RESUMO}

Neste texto discutimos o processo de construção do Projeto Político-Pedagógico de unidades escolares, com base em nossas experiências de atuação com profissionais da educação em algumas redes municipais. A partir de um recorte na malha urbana paulista, aanálise está focada em alguns municípios cuja população absoluta varia de 5.000 a 200.000 habitantes. Desse número para baixo está o conjunto de 93,95\% dos municípios, num universo total de 645, onde se encontram, num extremo, aqueles com apenas uma unidade escolar, que representa, em alguma medida, o centro da vida social de seus munícipes,e, noutro extremo, aqueles que contam com algumas dezenas de unidades escolares, numa rede de ensino bem mais complexa. Apesar das importantes diferenças entre eles, em função do contexto específico de cada um, em particular o seu tamanho, há características muito semelhantes, do ponto de vista educacional, como é o caso da falta de amplos e profundos debates em torno do planejamento, o que leva muitos a importarem modelos inadequados às suas realidades. Por conta disso, nosso objetivo éoferecer subsídios para se repensar as políticas educativas voltadas ao planejamento das escolas, com vistas à construção de seus Projetos Político-Pedagógicos.

Palavras-chave: Políticas públicas em educação; Projeto Político-Pedagógico; Planejamento escolar.

\section{RELIEF FOR POLITICAL-PEDAGOGICAL PROJECT CONSTRUCTION INTO MUNICIPAL'S SCHOOLS}

\begin{abstract}
In this paper we discuss the process of Pedagogical-Politic Project building into municipal schools based in our experiences with teachers of network schools. Since a snippet on "São Paulo" urban network, the focus is about the cities with absolute population is among 5,000 and 200,000 people. Into that group is 93,95\% of them, from 645 cities, among whom there are some of them who has only a school inside representing, by the way, the peoples' life center, whereas there's them tens and tens of schools into of them as a complex network of education. Although of important differences among them, because their singularities or their size, there is similar characteristics in the education field into them as a lack of larges and profound debates about educational planning, imposing for all of them to import inappropriate models to their realities. Thereupon our objective is to offer analysis and some reliefs to reconsider educational politics to schools planning objectifying the Pedagogical-Politic Project building.
\end{abstract}

Keywords: Public educational politics, Pedagogical-Politic Project, school planning. 


\section{Introdução}

Em breve completaremos 18 anos da aprovação da Lei de Diretrizes e Bases da Educação Nacional - Lei 9394/96. Ela consolidou, no plano normativo, um conjunto de princípios há muito tempo defendidos por um amplo setor dos movimentos sociais mais diretamente envolvidos com os temas educacionais, no contexto sobretudo, da abertura democrática dos anos 1980, após o regime da ditadura civil-militar. Um desses princípios, inclusive já consagrado na Constituição Federal de 1988, foi o da gestão democrática do ensino público. A ele podemos vincular o princípio da autonomia das escolas, que tem a ver, entre outras coisas, com a sua prerrogativa de construir seu próprio projeto pedagógico, com a participação da comunidade escolar, especialmente dos docentes. $\mathrm{Na}$ prática, no entanto, pouco se avançou. O projeto pedagógico oficial das unidades escolares é, quase sempre, representado por um documento que pouco tem a ver com o que de fato acontece nas escolas, e com aquilo que a escola pretende ser. Trata-se, portanto, de um documento que cumpre a formalidade da norma, mas de pouca substância de que se nutre a escola, inclusive de seus sonhos, ofuscados pela rotina pesada do cotidiano das escolas públicas.

Tendo em vista este cenário, neste texto discutimos o processo de construção do Projeto Político-Pedagógico (PPP), com base em nossas experiências de atuação com profissionais da educação em algumas redes municipais. A partir de um recorte na malha urbana paulista, a análise está focada em alguns municípios cuja população absoluta varia de 5.000 a 200.000 habitantes. Desse número para baixo está o conjunto de $93,95 \%$ dos municípios, num universo total de $645^{1}$, onde se encontram, num extremo, aqueles com apenas uma unidade escolar, que representa, em alguma medida,o centro da vida social de seus munícipes, e, noutro extremo, aqueles que contam com algumas dezenas de unidades escolares, numa rede de ensino bem mais complexa. Apesar das importantes diferenças entre eles, em função do contexto específico de cada um, em particular o seu tamanho, há características muito semelhantes, do ponto de vista educacional, como é o caso da falta de amplos e profundos debates em torno do planejamento, o que leva muitos a importarem modelos inadequados às suas realidades. Por conta disso, nosso objetivo é oferecer subsídios para se repensar as políticas educativas voltadas ao planejamento das escolas, com vistas à construção de seus PPP.

Não identificaremos os municípios e as escolas onde atuamos e coletamos alguns dados. Representaremos os mesmos, respectivamente, por letras e números. Os dados, na verdade, são utilizados como exemplos práticos, em nossas reflexões, que podem ter valor para aqueles que vivenciam situações semelhantes, com relação ao PPP, e que se reconhecem em uma das seguintes condições: a escola possui o PPP, mas o mesmo está desatualizado; a escola possui o PPP atualizado, mas já vislumbra a necessidade de novas discussões, por força da rotatividade dos professores; a escola não possui o PPP, porque ele nunca foi construído.

\section{Projeto Político-Pedagógico: importância do comprometimento de todos com o processo de sua construção.}

De forma bastante recorrente, ao se iniciar o processo de discussão sobre o Projeto Político-Pedagógico (PPP), logo vem à tona um imperativo quase que absoluto: a própria realidade, vista sob o prisma daqueles que vivem cotidianamente a escola pública. Isso impõe a necessidade de se problematizar, em primeiro lugar, com a comunidade escolar, 
qual é essa realidade vista por eles, o que resulta na compreensão de que nem sempre o que vemos é a realidade em si, mas uma interpretação da mesma, dentre as muitas possíveis. Provisoriamente, no início, falamos de condições de realidade ou de formação discursiva, lastreada nas possibilidades de enunciação que nos cercam e nos permitem afirmar - ou mesmo negar - o que está diante de nós. O real é marcado mais pela descontinuidade que pela continuidade, o que nos deixa perplexos diante de tudo que vivemos (Foucault, 1997).O lugar de onde olhamos marca o que vemos. Essa é uma discussão que se mostra frutífera no sentido, pelo menos, de desarmar o espírito daqueles que não veem possibilidade alguma de se pensar um projeto educativo livre de supostas amarras ou determinações vindas de todos os lados, e de várias formas. Sem compreender a autonomia relativa da escola não se pode dar o primeiro passo.

\section{Por que planejar? Por que construir o Projeto Político-Pedagógico?}

Reconhecer que a escola é condicionada, não determinada, nos termos de Freire, é a condição primeira para se responder outras questões fundamentais, quando se trata de construir o Projeto Político-Pedagógico da escola, dentre elas as que se colocam logo acima: Por que planejar? Por que construir o Projeto Político-Pedagógico?

Segundo Veiga (2003), há que se levar em conta a necessidade de mudança para se estabelecer um processo de construção do Projeto Político-Pedagógico da escola, cuja finalidade deve ser a melhoria da qualidade da educação. Para alcançá-la é necessário o levantamento de demandas reais, resultado de consensos provisórios entre todos os setores da escola, cada qual com seu olhar, nem sempre explícito, e muitas vezes conflitante com os demais.

Falar em inovação e projeto político-pedagógico tem sentido se não esquecermos qual é a preocupação fundamental que enfrenta o sistema educativo: melhorar a qualidade da educação pública para que todos aprendam mais e melhor. (...) A inovação regulatória ou técnica deixa de fora quem inova e, portanto, não é afetado por ela. Há uma separação entre fins e meios, em que se escamoteiam os eventuais conflitos e silenciam as definições alternativas em que se pressupõem definidos os fins e a inovação incide sobre os meios. (Santos apud Veiga, 2003, p.268 e 269).

Por isso mesmo, a construção do PPP na unidade escolar supõe desafios que demandam esforços constantes por parte da direção e da coordenação pedagógica, para que possa chegar não apenas à produção de um documento a ser apresentado aos órgãos superiores, mas alcançar o compromisso de todos com os acordos produzidos, em favor da mudança em direção a uma sociedade mais democrática. Tal tarefa requer eficiência e eficácia, assim compreendidas:

Eficiência: "execução perfeita de uma tarefa que se realiza."

Eficácia: as coisas que realmente importam ser feitas, "porque são socialmente desejáveis. A eficácia é atingida quando se escolhem, entre muitas ações possíveis, aquelas que, executadas, levam à consecução de um fim previamente estabelecido e condizente com aquilo que se crê." ( $p$ 16-17) (Gandin, 1997, p. 16-17). 


\section{Por que não planejar! Barreiras à construção do PPP.}

Há diversos obstáculos à construção do Projeto Político-Pedagógico em escolas públicas. A resistência à inovação ou mudança é um deles, levando alguns profissionais da educação até mesmo a boicotar o processo, até por força do desencanto com a escola e com a educação. Denegações práticas são outra forma de resistir: aceita-se a inovação no plano discursivo, mas a mesma é negada no campo da ação, ao longo do processo. Esse fenômeno não é estranho, se consideramos a transição de modelos de gestão da educação e das escolas mais autoritários e autocentrados para novos modelos mais abertos e com melhores chances de participação e de autonomia, tanto dos sujeitos, quanto das próprias instituições. Neste sentido, defendemos que é preciso prestar mais atenção a novas modalidades de autoritarismos que revestem práticas e discursos que se auto enunciam democráticos, e também a novas formas, mais democráticas, de se pensar e de se fazer que se anunciam. É comum encontrarmos gestores escolares que se autoproclamam democráticos, enquanto efetivam rotinas, procedimentos e decisões que negam parcialmente a participação do conjunto dos agentes escolares, ao mesmo tempo que nos deparamos com práticas criativas, inovadoras de gestão, caracterizadas pela abertura democrática.

Nesse lusco-fusco, marcado por projetos democráticos e projetos que preservam ranços autoritários, se dá a condução de reuniões de planejamento que ocorrem nas escolas. Destacamos a recorrência de decisões açodadas, marcadas pela injunção de prazos que são definidos fora do ambiente escolar, sob a justificativa de que não se tem muito tempo para pensar sobre elas. Por vezes não se trata apenas de falta de tempo, mas também de falta de informações adequadas, de objetivos e prioridades claros, o que leva muitos diretores, professores e coordenadores pedagógicos a manterem a tradição de decisões que se insinuam como democráticas, mas que revelam o oposto.

Considerando que as próprias concepções de planejamento decorrem de políticas concentracionistas, traduzidas por antigas divisões entre quem concebe a instituição - toma as principais decisões e estabelece suas diretrizes - e quem realiza a ação pedagógica, propriamente dita, ou seja, os docentes, Fusari (s/d) nos alerta que é preciso recuperar junto aos professores a importância do planejamento, para que possam conceber o próprio trabalho pedagógico em outros parâmetros e enfrentar os desafios atuais da educação. Sem a realização desse esforço junto aos docentes, as velhas concepções de que o planejamento representa um momento isolado, em geral no início do ano, antes de receber os alunos, e que resultará em formulários ou documentos preenchidos ao final do processo, prevalecerão e tudo continuará como está.

Valorizar o planejamento escolar, a construção do PPP, não decorre apenas de vontade política, mas de capacidade técnica. Muitos sabem da importância do planejamento, de se ter um projeto para a escola, pois isso se espalhou, cremos, por todo o território nacional e pelos corredores de todas as escolas públicas deste país. No entanto, nos deparamos, ao longo dos últimos anos, com diretores, coordenadores pedagógicos e professores que não sabem sequer por onde começar. Outros, pressionados pelos órgãos gestores da educação, sobretudo no âmbito dos municípios, lançam mão de projetos prontos ou fabricados por especialistas que não se dão ao trabalho, sequer, de ir até a escola, e de realizar um levantamento de demandas, recursos e prioridades da unidade escolar. 


\section{Como construir o PPP? Alguns apontamentos.}

Podemos estabelecer três etapas no processo de construção do PPP: (1) estabelecimento de prioridades, objetivos, metas e ações; (2) implementação das ações previstas e (3) avaliação do projeto. Descreveremos a seguir, a partir das nossas experiências em alguns municípios, nos últimos anos, o detalhamento de cada uma delas.

\section{(1) Estabelecimento de prioridades, objetivos, metas e ações.}

\section{Prioridades}

A construção do PPP supõe uma elevada reflexão coletiva das diversas concepções que afetam a escola: concepções de educação e de escola, de sujeito que ensina e que aprende, do papel social da escola, da avaliação. Para isso acontecer, a disponibilidade de tempo e a clareza da importância do processo de discussão tornam-se essenciais para se eleger bem as prioridades da escola. Em muitas situações, aos se construir o projeto político-pedagógico, as prioridades são escolhidas de forma apressada e pouco refletida. Confundem-se, nesses casos, processo democrático com eleições das mais variadas naturezas - no caso, as prioridades. As eleições têm sua importância, mas, sobretudo, têm seu tempo e seu lugar, que só um processo bem feito pode indicar. A reflexão coletiva deve envolver toda a comunidade escolar, e em todos os momentos (Arelaro, 2009), mas sem haver a domesticação da participação (Arroyo, 2008), condição para se obter o caráter de inovação (Veiga, 2003). Neste sentido, a primeira inovação a se estabelecer no processo de construção do PPP é, justamente, não repetir a já consolidada forma de participação ilustrada, indicada por Arroyo, na qual participam de fato aqueles que já sabem participar; nesse caso, há uma forma de participação que é válida ou aceita, em detrimento de outras, vistas como inadequadas. Superar essas estratégias autoritárias é condição para fazer emergir autonomia no espaço escolar, como uma utopia (Barroso, 1996).

Estabelecer prioridades para a escola e escrevê-las no PPP é, certamente, um ato que se realiza na direção do engajamento coletivo, para que se efetive uma forma de se fazer política educacional com caráter democrático. Assim, a discussão se inicia com a "escola dos sonhos" de todos que dela fazem parte. Não é um exercício fácil e simples, pois, em diversas escolas públicas por onde temos passado, tem-se a impressão de que se desistiu de sonhar com uma outra escola, já há muito tempo. Sem sonhos não há o que mudar, pois só ele faz emergir um horizonte novo. Nossa experiência mostra que, ao serem convidados a sonhar, uns e outros vão se colocando modestamente, não acreditando que aquilo vá surtir algum resultado positivo; alguns indagam, por exemplo, se sonhar não pode ser algo frustrante, porque alguns sonhos nunca serão realizados. Aos poucos, no entanto, há um sentimento geral de que tal etapa é mesmo importante, porque é o momento de se descolar um pouco da realidade vivida, percebida, construída socialmente. Ao mesmo tempo, quando o processo é bem conduzido, é possível analisar os valores neles contidos, indicando crenças, concepções de educação e de escola, bem como de sujeitos em formação. Uma plêiade de imagens, ainda um pouco esmaecidas, refletem uma luz fugidia de um lugar no qual se trabalha com o ensino, com a aprendizagem, com dúvidas, com metáforas, com exemplos; e tudo isso aponta para um lugar mais distante do que aquele em que nos encontramos, para uma sociedade mais promissora, em algum lugar do futuro. Por meio da manifestação dos sonhos, antes de tratarmos de prioridades e objetivos para a escola, colocamos os sujeitos que nela atuam no centro das atenções e do debate, para sabermos o que podemos e o que desejamos fazer na escola e na vida. É desejável que 
essas discussões remetam a alguns temas mais amplos, que funcionam como "pano de fundo" na construção do PPP, com o por exemplo: democracia, participação e autonomia. A boa compreensão desses conceitos é ponto de partida, porque eles servirão de referencial, porque estão nas bases do PPP. Algumas perguntas - O que se entende por democracia? O que se entende por participação? O que se entende por autonomia? - nos levam necessariamente a outras, igualmente importantes: A escola que se tem satisfaz a todos? Há que se promover mudanças? A escola que se tem já atingiu o nível de engajamento e qualidade que todos defendem? A aprendizagem dos alunos é satisfatória? Que escola se quer? Que aspectos demandam mudanças na escola? Essas mudanças são possíveis de se realizar? Tais perguntas servem para mobilizar o início do processo de planejamento.

Desses questionamentos surge a possibilidade de se estabelecer um bom diagnóstico que, segundo Gandin (1997) "é a parte de um plano que profere um juízo sobre a instituição planejada", ou ainda "o resultado da comparação entre o que se traçou como ponto de chegada [...] e a descrição da realidade da instituição como ela se apresenta." (p.29). Ele demanda duas atividades: a pesquisa e o juízo. Isto nos indica que entre a escola que se tem e a escola que se deseja ter há uma distância a ser percorrida. Quando essa distância se torna clara para todos os envolvidos no processo de planejamento pode-se considerar efetivado um processo amadurecido de reflexão na escola. Isso fundamentará as decisões relativas às prioridades, às estratégias, aos recursos, aos responsáveis e ao cronograma, tanto da construção do PPP, quanto do próprio cotidiano da unidade escolar.

Com base no que foi dito, consideremos a seguinte sequencia no processo de planejamento: primeiro os sonhos, depois os valores, depois as prioridades. A título de ilustração, nas várias escolas em que nos envolvemos a fim de se construir os seus respectivos PPP, identificamos alguns sonhos, dentre os quais destacamos:

unificar o trabalho realizado com a etapa do $1^{\circ}$ ao $9^{\circ}$ ano em um mesmo espaço, possibilitando melhor acomodação de alunos e professores; aprimorar os recursos tecnológicos; e obter maior segurança;

implantar projetos que fortaleçam o trabalho coletivo, desenvolvendo uma visão cultural e artística da comunidade escolar;

$>$ estabelecer um programa de formação continuada para professores e funcionários da escola;

$>$ firmar parcerias com a saúde para atender às demandas educacionais na área da psicologia e fonoaudiologia;

$>$ desenvolver projetos de leitura e escrita ao longo do processo de escolarização - do $1^{\circ}$ ao $9^{\circ}$ ano;

$>$ reconhecer a escola como local de conhecimento e crescimento, e que heja participação da comunidade

fortalecer a política de educação especial.

Neles reconhecemos alguns valores que merecem um exame mais acurado. $\mathrm{O}$ primeiro tem a ver com a redefinição do espaço escolar, cujo uso deve ser coletivo, e nesse espaço deve-se estabelecer uma visão de cultura e de desenvolvimento das artes plásticas, da representação, da dança, da música. Um segundo valor tem a ver com o princípio da formação continuada enquanto oferta pública aos profissionais da educação, de forma permanente, para que todos que convivem na escola tenham acesso aos diferentes saberes, e que, ao mesmo tempo, sejam reconhecidoscomo produtores de conhecimento. Um terceiro valor refere-se à construção de uma relação mais profícua entre educação escolar e 
outras áreas, como por exemplo, a da saúde, com vistas à melhoria das condições de aprendizagem dos alunos e do trabalho pedagógico realizado na escola. Por fim, um quarto valor aponta para o fortalecimento e aprofundamento das políticas de inclusão voltadas ao atendimento das demandas da educação especial.

Após esse levantamento é possível e desejável discutir quais as prioridades que a escola identifica nesse conjunto de sonhos e valores. A tendência, nesse momento, é realizar uma votação sobre um rol de ações possíveis, nem sempre articuladas com os desejos e compromissos da maioria. Ao acompanhar processos de discussão nas escolas municipais, identificamos que a alfabetização, a leitura e a escrita, aliadas às atividades lúdicas e artísticas, se destacam no universo das prioridades, uma vez que as políticas externas de avaliação de desempenho escolar tendem a estabelecer para a escola o que é prioritário. A estratégia da votação, não raro, leva à unanimidade, indicando, por vezes,a necessidade de um maior amadurecimento do processo, pois aqueles que se percebem como minoria, na defesa de prioridades, tendem a se submeter à vontade da maioria.

Com Barroso (2004), notamos que algumas lógicas podem surgir nesse processo:

Lógica estatal - reduzir o processo à mera "modernização administrativa", "melhorando os mecanismos de planeamento e controlo". Lógica de mercado - construção de um mercado educativo. "Desregulação da intervenção do Estado" Lógica corporativa - considera a autonomia na concepção de "bem-exclusivo" do corpo docente e não como um bem público. Lógica comunitária - "processo social que envolve todos que atuam na escola e também os pais e a comunidade atendida" (p.62-63).

Participando das discussões sobre o Projeto Político-Pedagógico nas escolas, em alguns municípios, notamos a presença maior da lógica estatal e da lógica corporativa. Isso se deve, talvez, mais à herança de um modus operandi que rege os processos de planejamento escolar do que a uma deliberação do corpo docente ou de outros setores da escola. Quebrar as práticas decorrentes dessas lógicas é uma tarefa de médio e longo prazos.

Sobre as prioridades estabelecidas nas escolas, destacamos algumas que mais nos chamaram a atenção. Cremos que elas revelam enunciados dos quais podemos inferir concepções de escola e de educação daqueles que atuam nas unidades educacionais.

Alfabetização, leitura e escrita, e atividades lúdicas, artísticas e de raciocínio lógico matemático no $1^{\circ}$ ao $9^{\circ}$ ano;

$>$ Trabalho coletivo da comunidade escolar interna;

Fortalecimento da participação dos pais e ou responsáveis na formação dos educandos;

> Demanda de novas políticas para o atendimento da educação especial, contando com parcerias com outros profissionais, para dar suporte ao atendimento dos alunos da inclusão que estão inseridos na rede regular de ensino do município: psicólogo, fonoaudiólogo, assistente social (equipe multifuncional).

Essas prioridades acentuam temáticas de primeira grandeza nas escolas públicas: fortalecimento do processo de alfabetização, associado às experiências lúdicas com as crianças; cuidado com as relações intersubjetivas; aprofundamento da relação escolacomunidade; políticas sólidas para o atendimento de estudantes com necessidades especiais, incluindo acesso a profissionais da saúde, nas áreas que podem colaborar diretamente no desempenho daqueles que apresentam dificuldades específicas. Todas se 
referem a gargalos que as escolas públicas enfrentam. Haja vista a constituição de uma Secretaria para atendimento de ações na esfera das necessidades especiais - a SECADI ${ }^{2}$, e a gama de programas e projetos financiados pelo governo federal nessas áreas, dentre as quais, o Pacto pela Alfabetização na Idade Certa (PNAIC), o Programa de Fortalecimento dos Conselhos Escolares (CE), que inclui também a formação de conselheiros dos Conselhos Municipais de Educação (CME).

Após a escolha das prioridades, há outra etapa do processo, constituída pelo estabelecimento de objetivos, metas e ações no âmbito do planejamento. Diversas experiências de planejamento escolar fracassam por não estipular mais claramente essa etapa, indicando uma divisão perversa e persistente entre planejar e executar na escola.

\section{Objetivos}

Os objetivos servem para orientar o caminho para se alcançar as prioridades; e cada uma delas deve ter seus objetivos muito bem definidos. Para tanto, é importante objetivos de médio prazo; anuais, por exemplo, uma vez que as prioridades se referem a todo o período de vigência do PPP, que varianormalmente de dois a quatro anos. Assim, osobjetivos de curto e médio prazos facilitam a compreensão do percurso a percorrer.

Indicamos, a seguir, alguns objetivos de algumas escolas nas quais atuamos, e que sãorecorrentes, dada sua abrangência: (1) auxiliar os professores alfabetizadores na realização de atividades coletivas, com vistas ao aprimoramento do processo de alfabetização em todas as turmas; (2) ensinar noções artísticas (artes cênicas, artes plásticas, música, dança); (3) ampliar a capacidade de raciocínio lógico-matemático; (4) efetivar o trabalho coletivo na escola, através de grupos que assumam tarefas específicas relacionadas ao PPP; (5) estabelecer, no prazo de vigência deste PPP, atendimento de diversos profissionais no município, para auxiliar a efetivação da inclusão de alunos com NEE; (6) ampliar a participação dos pais ou responsáveis nas atividades propostas pela escola, inclusive naquelas que são realizadas em casa, pelos alunos.

Analisando os objetivos acima, notamos que há alguns temas que permanecem como demandas de atenção e formação dirigidas aos responsáveis pela oferta educacional nos municípios: alfabetização, educação artística, raciocínio matemático, trabalho coletivo, alunos com NEE e participação dos pais. Isto ocorre, provavelmente, por conta de políticas que ainda não atingiram um patamar de qualidade capaz de gerar forte impacto positivo na escola básica, em termos de formação continuada e formação inicial, esta última atingida por uma realidade bem difícil, de desvalorização da carreira docente, conforme nos indica Gatti (2009, p. 66), que, em sua pesquisa, destaca:

Nos resultados, as falas dos estudantes em relação à docência e ao "ser professor" foram permeadas de contradições e contrastes. Os sentidos que atribuem à imagem da profissão retratam sempre duas perspectivas de análise. Ao mesmo tempo em que conferem à docência um lugar de relevância na formação do aluno e que o professor é reconhecido pela sua função social, retratam que se trata de uma profissão desvalorizada (social e financeiramente) e que o professor é desrespeitado pelos alunos, pela sociedade e pelo governo. 


\section{Metas.}

As metas representam o esforço de se estabelecer indicadores de resultados que levam aos objetivos propostos. Tais indicadores devem ser alcançados em etapas bimestre a bimestre, por exemplo, dado que essa é uma forma de divisão do tempo que todas as escolas básicas que conhecemos utilizam. Utilizar essa dinâmica é uma maneira de a escola se aproximar melhor dos temas de maior relevância, mas que dificilmente ocupam o lugar que merecem, dada a concretude das demandas específicas e rotineiras do cotidiano escolar. No processo de construção do PPP é extremamente importante que a escola enfrente seus maiores desafios em etapas que guardem íntima relação com os tempos mais conhecidos dos professores, coordenadores pedagógicos, diretores escolares, alunos e seus familiares. Destacamos algumas metas que nos chegaram a partir do acompanhamento de diversas escolas municipais. São elas: (1) realizar um evento, no qual toda a escola efetivará atividades de leitura e escrita; (2) consolidar o trabalho coletivo através do desenvolvimento de um trabalho único que será realizado no semestre, por todos os professores, servidores técnico-administrativos e de suporte, e que favoreça a interdisciplinaridade; (3) obter ajuda de profissionais ligados às deficiências; (4) realizar reuniões com profissionais de áreas afins, para melhor atuar junto aos alunos comdeficiências; (5) realizar reuniões com os pais para tratar das questões da inclusão; (6) adquirir materiais especializados para a inclusão; (7) discutira cultura da exclusão, junto com toda a comunidade escolar.

A respeito de tais metas, assinalamos que elas revelam, dentre outras coisas, as dificuldades de lidar com a inclusão na escola; isso porque há ainda umadistância entre políticas de inclusão e o cotidiano das escolas por onde passamos.

\section{(2) Implementação das ações previstas.}

Ao se discutir ações pertinentes às metas e objetivos, as professoras e professores tendem a trazer aquilo que já realizam no seu cotidiano para o interior do PPP. Esse processo merece uma análise mais acurada. Em primeiro lugar, o PPP, em nossa maneira de pensar, não deve ser algo exógeno e estranho para a escola, pois não se cancela o real e o cotidiano das pessoas, como se tudo o que pensam e fazem estivesse fadado ao fracasso e representasse, de saída, insucesso. Em segundo lugar, e como alerta, propomos que se avalie o que se faz, para que se responda a uma pergunta simples: por que fazemos o que fazemos? Ambas nos levam a um terceiro lugar, que pode ser traduzido em uma nova pergunta: como dar novo significado ao que fazemos, no seio dos debates do PPP, que instauram o novo como possibilidade de ação e de pensamento? A resposta a esse questionamento tem se revelado aos poucos, para nós: se o que fazemos não se encaixa no PPP, então é o PPP que precisa de revisão! A despeito da possibilidade dessa resposta ser interpretada como produto da arrogância de educadores que nada querem mudar - o que se nos apresenta, de vez em quando -, não cremos que é isso que se está enunciando. O que se está buscando propor é que o PPP não deve ser elaborado contra os saberes dos profissionais que há tanto tempo se dedicam à formação dos estudantes, na escola pública, mas na direção de consolidar boas experiências e de propor questionamentos sobre aquelas outras que não atendem bem às necessidades da escola e, sobretudo, dos alunos.

Feita essa ressalva, apresentamos a seguir algumas ações que nos têm chegado, a fim de conhecermos um pouco do que se passa nas escolas públicas, em sua dimensão do saber-fazer cotidiano: (1) sarau literário; (2) cenas de leitura (teatro e literatura); (3) cinema e literatura (filmes sobre leitura); (4) contação de histórias, com encenação; (5) 
produção de jornal; (6) produção de mural; (7) mostra de trabalhos literários dos alunos; (8) leitura com pais; (9) mural dos pais; (10); jogos (tabuada, desafios, caça ao tesouro); (11) reuniões de pais (bimestral); (12) Conselho de Escola; (13) formatura (com confraternização ao final); (14) dia da família; (15) reuniões e encontros com os profissionais que já dão atendimento, para troca de experiências; (16) aquisição de materiais que ensinam estratégias de como trabalhar em sala de aula com alunos com deficiências.

Ressaltamos que todas as ações acima alinham-se com as principais demandas das escolas que acompanhamos no processo de construção do PPP. Vale dizer também que, por mais que essas ações indiquem fortes semelhanças com o que se faz em outras tantas escolas públicas, há sempre uma maneira muito própria de cada uma. Assim, com Teixeira (2002, p.40), reconhecemos a escola como

(...) um sistema sociocultural constituído por grupos relacionais que vivenciam códigos e sistemas de ação. Perceber o aspecto simbólico da gestão da instituição de ensino, presente no discurso e na ação cotidiana da escola, supõe situá-la numa dimensão que privilegia a cultura escolar.

\section{(3) Avaliação do PPP.}

Após a definição dos objetivos, metas e ações, inicia-se a discussão sobre as formas de avaliação do projeto. Isso significa prever os procedimentos e os momentos mais adequados para se retomar as etapas de planejamento, de implementação e, se necessário, proceder ao replanejamento de algumas ações, buscando salvaguardar as prioridades e objetivos estabelecidos, alterando apenas aspectos vinculados a metas e ações. Isso é necessário para se evitaralteração das diretrizes do projeto a cada avaliação, o que pode resultar no travamento do mesmo, pulverizando as ações da escola.

Baseados nesses pressupostos, propomos que a avaliação se faça mediante alguns cuidados, ao longo do processo de implementação do PPP. São eles: (1) garantia de que todos os envolvidos possam ter plena clareza de cada etapa a ser implementada; (2) garantia de que todos possam intervir,afim de se comprometerem com o conjunto e com cada uma das etapas; (3) garantia do princípio, com relação a planos, de que quem concebe participa da implementação e da avaliação, conforme defende Ferreira (apud Arelaro, 2009, p.902).

Sugerimos que a avaliação se realize a cada ação executada, com o devido registro de seus resultados. Essa tarefa supõe o caminho inverso ao da construção do PPP: avalia-se cada ação, em si, perguntando-se, em seguida, se ela se deu no interior da meta correspondente, que por sua vez refere-se a um determinado objetivo, do qual se espera que se cumpra a prioridade que o antecede. Assim, esquematicamente poderíamos visualizar o processo da seguinte maneira:

Esquema de construção do PPP:

\begin{tabular}{|l|l|l|l|l|l|}
\hline Sonhos & Valores & Prioridades & Objetivos & Metas & Ações \\
\hline
\end{tabular}

Esquema de avaliação do PPP:

\begin{tabular}{|l|l|l|l|l|l|}
\hline Ações & Metas & Objetivos & Prioridades & Valores & Sonhos \\
\hline
\end{tabular}


A proposta contida no esquema acimapode requerer algumas adaptações, ou mesmo um movimento de implementação e revisão poderá ser admitido, se se considerar necessário e produtivo, de acordo com as opções de cada escola.

\section{Considerações Finais.}

Nosso objetivo com o presente texto foi oferecer subsídios para o debate em torno da construção do Projeto Político-Pedagógico em escolas públicas. Dimensionar as dificuldades dessa empresa é condição para que se possa superá-las desde o momento em que se decide pelo processo de sua construção. No entanto, consideramos que as políticas públicas, produzidas no âmbito da União e dos Estados, entes federados mais fortes, se realizam no chão dos municípios e das redes públicas. Efetivar, portanto,políticas públicas que propiciem o alcance de melhores patamares qualitativos para a educação depende, em boa parte, do que ocorre no interior das escolas. No entanto, temos consciência de que opções basistas, ou seja, aquelas que defendem que tudo pode ser melhorado em educação se as escolas melhorarem suas performances e seus escores, não passa de engodo, e repudiamos tais propostas. No texto que aqui se encerra, propomos que se dê mais atenção e suporte às escolas, a seus profissionais (os docentes, os coordenadores pedagógicos, os diretores e demais profissionais de apoio) e, sobretudo, aos alunos e seus familiares que, em última análise, são os portadores do direito subjetivo à educação de qualidade.

O estabelecimento de políticas públicas em educação produz desafios para as escolas e, normalmente alteram o cotidiano em que elas se inserem. É recorrente o fato de que os profissionais da educação, que atuam nas escolas, aqueles que serão responsáveis pela sua implementação, nem sempre são ouvidos ou têm oportunidade de se manifestar quanto ao processo de elaboração das mesmas. Sendo assim, aqueles que planejam nem sempre são aqueles que executam tais medidas. Tais políticas, que aqui as denominamos de "focais", ou seja aquelas que focam diretamente o cotidiano escolar, demandam discussões daqueles que atuam diretamente nas escolas para que possam ganhar alguma legitimidade. Nesse sentido, a elaboração do PPP pode ser um exemplo de política educacional, destinada a promover modificações na escola que pode ser assumida por professores, coordenadores pedagógicos, diretores e diretoras, para se alcançar melhores patamares de qualidade.

Não se trata de não se efetivar políticas focais, principalmente considerando que, em algumas delas, os recursos são bastante significativos e podem auxiliar muito as escolas que os recebem. O que defendemos é que esses aportes e essas políticas focais sejam discutidas e, em alguma medida, implementadas para que promovam um maior adensamento das políticas locais. O Projeto Político-Pedagógico é uma ação que, de alto a baixo da hierarquia educacional, se apresenta como uma das mais avançadas formas de aprofundar experiências democráticas e consolidar diferentes e inovadoras formas de participação, produzindo criativas maneiras de autonomia relativa nas escolas. Quaisquer políticas que venham somar-se a esse processo devem receber nosso apoio, para que se superem, enfim, as tradicionais heranças patrimonialistas que tanto retrocesso representaram, e ainda representam, na história da educação em nosso país. 


\section{Referências}

ARELARO, Lisete. Formulação e implementação das políticas públicas em educação e as parcerias público-privadas: impasse democrático ou mistificação política? In: Educação \& Sociedade, Campinas, vol. 28, n. 100 - Especial, p.899-919. Disponível em: http://www.scielo.br/pdf/es/v28n100/a1328100.pdf Acesso em 10/04/2009.

ARROYO, M.G. Gestão democrática: recuperar sua radicalidade política? In: CORREA, B. C.; GARCIA, T. O. (orgs). Políticas Educacionais e organização do Trabalho na escola. São Paulo: Xamã, 2008. (p.39-56).

BARROSO, João. Autonomia das escolas: uma ficção necessária. Revista Portuguesa de Educação, ano/vol. 17, $\mathrm{n}^{\circ}$ 002, p.49-83, Universidade do Minho, Braga, Portugal, 2004, p.49-83. Disponível em: http://redalyc.uaemex.mx/pdf/374/37417203.pdf Acesso em 28 de fevereiro de 2012.

O estudo da autonomia da escola: da autonomia decretada à autonomia construída. In BARROSO, João. O estudo da Escola. Porto: Porto Ed., 1996.

FOUCAULT, Michel. Arqueologia do Saber. Trad. Luiz Felipe Baeta Neves. $5^{\text {a }}$ ed., Rio de Janeiro: Forense Universitária, 1997.

FUSARI, José Cerchi. O Planejamento do Trabalho Pedagógico: Algumas Indagações
e Tentativas
http://www.crmariocovas.sp.gov.br/pdf/ideias 08 p044-053

GANDIN, Danilo. Planejamento como prática educativa. 9a edição. São Paulo: Loyola, 1997.

GATTI, B. A. Atratividade da carreira docente no Brasil. Fundação Carlos Chagas. São Paulo. 2009. Disponível em: http://revistaescola.abril.com.br/pdf/relatorio-finalatratividade-carreira-docente.pdf Acesso em 02-05-14.

RISCAL, Sandra Ap. Gestão democrática no cotidiano escolar. São Carlos: EDUFSCar, 2009. (Coleção UAB-UFSCar).

TEIXEIRA, L.H.G. Cultura Organizacional e Projeto de Mudança em Escolas Públicas.Campinas: Autores Associados, São Paulo: UMESP, ANPAE, 2002. Disponível em: $\quad$ http://books.google.com.br/books?id=yesDQwBZhk0C\&pg=PA2\&hl=pt-

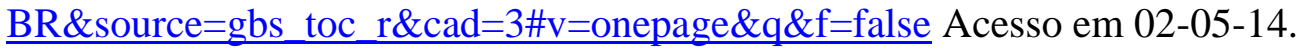

VEIGA, Ilma Passos Alencastro. Inovações e projeto político-pedagógico:uma relação regulatória ou emancipatória?Cad. Cedes, Campinas, v. 23, n. 61, p. 267-281, dezembro 2003.

Notas ${ }^{1}$ Fonte: Sinopse do Cento Demográfico de 2010. Disponível em:
http://www.censo2010.ibge.gov.br/sinopse/index.php?uf=35\&dados=0 Acesso em 20-03-14.
${ }^{2}$ Secretaria de Educação Continuada, Alfabetização, Diversidade e Inclusão. Disponível em:
http://portal.mec.gov.br/index.php?option=com_content\&view=article\&id=290\&Itemid=816\&msg=1
Acesso em 30-04-14.

Recebido: $\quad$ março/14 Aprovado: junho/14 